\title{
Aspectos institucionais da formação de preços
}

Institutional aspects of price formation

\author{
Rogerio P. de Andrade (1) \\ Alex Wilhans Antonio Palludeto (2) \\ (1) Universidade Estadual de Campinas \\ ${ }^{\text {(2) }}$ Universidade Estadual de Campinas
}

\begin{abstract}
According to the traditional view of price formation, prices are the result of the interactions of supply and demand. An equilibrium price is one where the quantity demanded equals the quantity supplied. The price system provides a mechanism whereby changes in supply and demand conditions affect the allocative efficiency of resources. However, in an important measure, prices are not completely determined in the market by supply and demand, but by other factors such as power, market structures, conventions, rules, routines etc. The purpose of this paper is to investigate the role and influence of a variety of institutions in the pricing process, with particular emphasis on conventions.
\end{abstract}

\section{Keywords}

pricing, institutions, conventions, heterodox economics.

JEL Codes B50, B52, D02, E31.

\section{Resumo}

De acordo com a visão tradicional do processo de formação de preços, estes resultam das interações entre oferta e demanda. Um preço de equilíbrio é aquele no qual as quantidades demandadas se igualam às quantidades ofertadas. O sistema de preços fornece um mecanismo por meio do qual mudanças nas condições de oferta e demanda condicionam a eficiência alocativa dos recursos. No entanto, em grande medida, os preços não são determinados no mercado pela oferta e demanda nessa acepção estrita, mas por outros fatores como poder, estruturas de mercado, convenções, regras, rotinas etc. O propósito deste artigo é investigar o papel e a influência de uma variedade de instituições no processo de formaçãa de preços, com particular ênfase nas convenções.

\section{Palavras-chave}

formação de preços, instituições, convenções, economia heterodoxa.

Códigos JEL B50, B52, D02, E31. 


\section{Introdução}

De acordo com a visão tradicional da formação de preços, estes são o resultado de interações entre oferta e demanda. Com efeito, desde sua formulação inicial mais bem-acabada por James Steuart (1767), oferta e demanda aparecem como pilares da teoria dos preços nos mais diversos livros-textos que a contemplam enquanto objeto. De acordo com essa perspectiva, aumentos nos preços indicam excesso de demanda em relação à oferta. Os preços ajustam-se até que oferta e demanda sejam equivalentes. A curva da demanda capta quanto os agentes desejam demandar a cada preço, e a curva de oferta expressa quanto os agentes desejam ofertar a cada preço. O preço de equilíbrio é aquele no qual a quantidade demandada iguala-se à quantidade ofertada. Assim, o sistema de preços oferece um mecanismo de ajustamento em que mudanças nas condições de oferta e/ou demanda condicionam a eficiência da alocação de recursos.

No entanto, em grande medida, os preços não são completamente determinados no mercado por demanda e oferta nessa acepção estrita, mas por uma multiplicidade de outros fatores como poder, estruturas de mercado, convenções, regras, rotinas, entre outros, que moldam a própria atividade mercantil e, assim, aquilo que se apresenta, à primeira vista, como simples resultado das forças de oferta e demanda (Beckert, 2011). Conforme destaca Hodgson (2015, p. 131):

(...) the institutional structures and detailed mechanisms of real-world markets have been widely neglected. There has been little discussion of how specific markets are structured to select and authenticate information and of how prices are actually formed. Economists refer to the forces of supply and demand and locate market equilibria at the intersection of their curves in price-commodity space, but until recently they have offered little discussion of the mechanisms through which these forces operate. Instead, the market has been treated as a relatively homogeneous and undifferentiated entity, with little consideration of different market mechanisms and structures.

Nesse sentido, o objetivo deste artigo é investigar o papel e a influência das instituições no processo de formação de preços, em particular as convenções.

A presente discussão sobre as instituições na formação de preço inicia-se com os insights de Hugh Townshend sobre o caráter convencional dos preços. As convenções ajudam a garantir uma relativa estabilidade de preços. Ao estabilizar os movimentos de preço e, em certa medida, torná-los previsíveis, as convenções contribuem para estabilizar o poder de compra dos agentes e para a elaboração de cálculos prospectivos. 
Uma instituição característica do mercado de bens é a precificação por meio de uma adição aos custos da firma (cost-plus pricing). As firmas recorrem a essa "regra de bolso" porque a mesma propicia que suas atividades continuem ao longo do tempo, isto é, se reproduzam. Conforme argumenta Velthuis (2013, p. 10), os preços "do not 'misteriously emerge from the market' (...) but are instead social formations or social constructions and form part of the established rules of the game that producers tacitly obey". Além disso, demandas por um "preço justo" são também fortemente disseminadas, ${ }^{1}$ especialmente da parte de agentes consumidores.

As instituições também operam no mercado de trabalho, mediante o papel exercido por "fatores normativos", como o costume e a preocupação com a "justiça" (fairness), que influenciam a estrutura de salários e os processos de barganha salarial, juntamente com as "forças de mercado" e que moldam essas próprias forças. Nesse âmbito, o estabelecimento formal do salário-mínimo e/ou de outros mecanismos, formais ou informais, que assegurem um piso inferior ao pagamento à força de trabalho considerado socialmente aceito, desempenha um papel relevante na organização do mercado de trabalho.

Por fim, este artigo também oferece uma interpretação da inflação baseada no papel das instituições. A inflação é vista como o resultado global de mudanças de custos, variações no grau de utilização da capacidade em virtude de alterações nas condições de demanda efetiva, aspirações conflitantes a respeito da distribuição de renda e colapso de arranjos institucionais familiares já estabelecidos.

\section{Sobre as instituições}

A literatura acerca das instituições e do papel que elas ocupam no tecido social, particularmente na vida econômica, tem longa trajetória. De fato, o tratamento das instituições jamais esteve ausente dos escritos de Smith,

1 A concepção de que as relações de troca devem ser pautadas por um "preço justo" é recorrente ao longo da história do pensamento econômico e encontra paralelo nos escritos de diversos pensadores escolásticos medievais, particularmente associados a Tomás de Aquino (Backhouse, 2002). Ainda que seja possível argumentar que o conceito escolástico de preço justo se aproxima da concepção de preço formado em mercados de concorrência perfeita, convém destacar que o significado dessa categoria na filosofia escolástica é bastante diverso da tradição liberal (Monsalve, 2014). 
Mill, Marx, Marshall, entre outros. No entanto, conforme destaca Rutherford (1996), o tratamento sistemático das instituições como elementos fundamentais para a compreensão da vida econômica tem nos trabalhos de Thorstein Veblen, Wesley Mitchell, John R. Commons e Clarence Ayre seu passo inicial decisivo. A tradição associada aos trabalhos desses autores e seus desdobramentos posteriores, ainda que não conformem um todo homogêneo, tem sido geralmente denominada de "Velha" Economia Institucional, como contraposto ao conjunto de estudos sobre as instituições, particularmente da segunda metade do século XX, associado à economia neoclássica - contemplando autores como Ronald Coase, Oliver Williamson, Douglass North, entre outros - denominado de "Nova" Economia Institucional (Rutherford, 1996).

Deixando de lado o debate, suficientemente amplo e complexo, acerca das contribuições de ambas as correntes e seus eventuais pontos de discordância e de contato, ${ }^{2}$ para os propósitos do presente artigo, convém observar que o significado das instituições e suas implicações no âmbito econômico são largamente inspirados na "Velha" Economia Institucional e nos demais autores que desenvolveram trabalhos nessa mesma tradição.

Nesse sentido, as instituições podem ser entendidas como as condições estruturais sempre presentes, ou procedimentos generalizados, para as ações humanas mantidas (e mudadas) pela prática. Os agentes recorrem a elas e as reproduzem por meio da ação, mas as instituições existem independentemente de qualquer agente isolado, que atua a partir delas. Isto é, as instituições e o comportamento intencional que as mesmas possibilitam são dois elementos distintos: as ações (a agência humana) pressupõem a preexistência e a relativa autonomia de um conjunto de estruturas sociais (como hábitos, convenções, regras, normas, rotinas etc.) que não devem ser identificadas com a própria ação. Há uma interdependência mútua e irredutível entre agência humana e estrutura, mas uma não se reduz a outra (cf. Lawson, 1997, cap. 12).

Segundo Walter Neale (1994, p. 402):

'Institution' is the word that evolutionary (institutional) economists use for the regular, patterned behaviour of people in a society and for the ideas and values associated with these regularities. Various phrasings have been used to define institutions or an institution: a usage that has become axiomatic by habituation; collective action in control of individual action; widely prevalent, highly standardized social habits; a way 
of thought or action embedded in the habits of a group or the customs of people; prescribed patterns of correlated behaviour.

Em termos mais gerais, as instituições podem ser entendidas como "socially shared patterns of behavior and/or of thought" (Dequech, 2009, p. 70). Nesse sentido, é possível também considerar que as instituições contemplam "structured processes of interaction (collecting together rules, relations and positions as well as habits and other practices), that are relatively enduring and identified as such" (Lawson, 1997, p. 318). Do mesmo modo, as instituição são, por conseguinte, "cultural scripts providing orientation for actors under conditions of uncertainty" (Beckert, 2011, p. 767). Assim concebidas, as instituições podem ser formais, quando possuem um caráter jurídico, legal, ou informais, quando não o possuem (Dequech, 2009).

É importante ressaltar que, uma vez que se assume que a agência humana, ou seja, o próprio comportamento humano, não se reduz às estruturas sociais, entre as quais as instituições, estas não devem ser concebidas como um elemento social estático, resistente a mudanças e, portanto, como limitante do comportamento humano. Em outras palavras, parece ser um equívoco considerar que as instituições correspondem a um traço social persistente e, assim, que os processos de mudança devem ser buscados fora delas. ${ }^{3}$ Pelo contrário, "[i]nstitutions both constrain and enable behavior" (Hodgson, 2006, p. 2). Desse modo, as instituições estão abertas à agência humana, apresentando tendências de mudança e permanência a depender da forma específica que a instituição assuma (normas, regras, convenções etc.) e da teia de demais instituições com as quais tem relação mais estreita. Comportamentos inovadores e criativos, parte substantiva dos quais possibilitada por determinadas instituições, são também uma característica importante da realidade econômica e podem transformar as estruturas sociais nas quais operam de dentro. De fato, "social structures, including, of course, institutions, exist as a process of reproduction and transformation" (Lawson, 2003, p. 184).

\section{A dimensão convencional dos preços}

As convenções, enquanto uma forma institucional, podem ser entendidas

3 Para uma crítica da suposta dicotomia presente em Veblen entre as instituições como elemento resistente à mudança e a tecnologia como dimensão promotora de transformações sociais, ver Lawson (2003). 
como padrões informais de comportamento ou pensamento socialmente compartilhados. Nesse sentido, as convenções são consideradas instituições informais. Conforme argumenta Dequech (2009), uma convenção possui ao menos duas características adicionais que outras instituições podem não ter: a) quando seguida conscientemente, uma convenção é seguida ao menos em parte porque outros a estão seguindo e não, ou não somente, porque há uma pressão externa para tal; b) é, em certo grau, arbitrária, ou seja, historicamente contingente.

A ideia de que convenções operam na formação de preços implica que os preços são definidos a partir de um "acordo implícito geral", e que eles permanecerão estáveis até que informação relevante venha à tona; "acordo" este que poderia, em princípio, apresentar-se de outra forma. Há, porém, uma precondição fundamental para que determinada convenção se efetive enquanto componente formador de preços: os preços resultantes devem garantir a reprodução da economia em suas bases capitalistas. Em outras palavras, o processo de formação de preços deve ser capaz de repor, com lucro, as condições daquela atividade na qual se opera, garantindo, portanto, os pré-requisitos de sua ampliação.

À primeira vista, essa afirmação parece indicar que, de certo modo, o processo de formação de preços não é contingente e, portanto, não seria expressão de uma convenção. Contudo, diversas modalidades de precificação podem garantir que a economia capitalista como um todo se reproduza; aquela socialmente selecionada, ainda que de um grupo mais restrito de padrões de conduta possíveis, continua sendo historicamente contingente, de tal forma que o entendimento das razões pelas quais aquele modo específico foi eleito requer o exame das condições concretas nas quais está incorporado.

A compreensão dos preços como uma convenção significa reconsiderar os determinantes principais do modo pelo qual são formados. Essa ideia, apesar de não ser inteiramente nova, não recebeu a devida ênfase nem foi mais elaborada na literatura econômica de forma sistemática.

Townshend (1937) parece ter sido o autor que, pioneiramente, identificou esse aspecto "convencional" na determinação de preço, chamando a atenção para a importância da estabilidade de preços na formação de expectativas e na tomada de decisão. No mundo real, há processos subjacentes que normalmente dificultam que os preços flutuem fortemente. Para Townshend (1937, p. 161-162), esse aspecto deve expressar: 
either a conventionality of outlook causing stability of expectations as to the money-prices of durable assets of certain kinds, or else the conventional maintenance of some degree of stability of the money-price of the only other exchangeable value, viz. labour - that is to say, a conventionally stable wage-unit. (...) Perhaps economic (price-) stability really depends on the prevalence of custom in regard to price-offers among the majority who all "think" alike, combined with the prevalence of a divergency of views among those who think for (literally, for) themselves. ${ }^{4}$

A "força do hábito" e a "prevalência dos costumes" engendram a perspectiva convencional na formação de preços e formam a base da estabilidade. A formação de convenções de estabilidade de preços revela a busca de mecanismos, socialmente definidos, para a estabilização do poder de compra, bem como a possibilidade de cálculos (correntes e prospectivos) a partir de uma base percebida como mais segura. Ao se considerar os preços como fenômenos convencionais, torna-se possível embarcar em processos de tomada de decisão em que a necessidade de regras estáveis esteja sempre presente.

Mesmo não estando totalmente elaborado, esse insight - que instituições de tipos variados, e em particular as convenções, desempenham um papel importante na formação de preços - era familiar a vários autores. Vejamos algumas das considerações presentes na literatura que parecem emblemáticas da dimensão institucional, sobretudo convencional, do processo de formação de preços.

Esse aspecto não escapou da análise de George Shackle (1972, p. 112):

If price stability, in reality, is not ensured by a direct governance of prices exerted through human reason by visible, objective circumstances which are themselves stable, then the practical needs of business and the workability of life demand that it be conjured ex nihilo by tacit, instinctive agreement, that is, by convention. For price stability of some degree is an indispensable support for stability of the rules of the business game and those of the broader game of survival itself. Stability by convention (...) has to serve instead of stability determined by reason and knowledge.

Para Roy Harrod (1952), as instituições também têm papel importante nas decisões de preços. O recurso às "regras razoavelmente simples" para se chegar a um preço evita os obstáculos associados à falta de praticidade dos cálculos dos valores marginais de cada bem e o conjunto associado de equações em um processo de produção complexo. O procedimento práti-

4 George Shackle (1972, p. 226-228) e Bruce Littleboy (1990, p. 288) parecem ter sido os únicos autores a reconhecerem a originalidade dos insights de Townshend. Para Littleboy, por exemplo, enveredar por esse caminho - isto é, considerar todos os preços como convencionais - significa invalidar completamente a ideia de agentes otimizadores. 
co e simples mais comumente usado é uma espécie de "ritual" baseado no princípio do custo total (Harrod, 1952, p. 164).

No entanto, embora as convenções proporcionem estabilidade, os preços sofrem a influência de vários fatores que podem vir a causar uma ruptura dessa estabilidade. Num mundo onde a inovação é o principal veículo para a acumulação de capital e a decomposição/recomposição das posições relativas, os preços são, como consequência, passíveis de mudança. A novidade leva à necessidade de revisar um dado (e familiar) conjunto de preços: "The real business of the market is a continual patching and piecemeal improvement of an always obsolescent set of prices" (Shackle, 1972, p. 268). As decisões de preços estão estreitamente relacionadas à expectativa de estabilidade corrente e futura, mesmo que a expectativa de possíveis mudanças esteja presente.

Testadas e aceitas pelas práticas sociais e experiências corriqueiras, as convenções oferecem o fundamento para possíveis ações bem-sucedidas baseadas na informação encravada nos preços. As regras desse jogo, que é instável por natureza, requerem algum tipo de estabilidade para dar suporte às decisões. ${ }^{5}$

Preços que permanecem em um nível particular por algum tempo ganham sanção e autoridade. Os agentes entendem esses preços como "corretos" e "justos" e, com o passar do tempo, acostumam-se com eles. ${ }^{6}$ Preços "familiares" tornam-se uma referência a partir dos quais os agentes adaptam suas práticas. Nesse sentido, são os preços que trazem algum tipo de coesão mútua para uma determinada realidade socioeconômica (Shackle, 1972, p. 227). Como disse John Hicks, os preços têm uma "função social" (Hicks, 1974, p. 85).

Para Arthur Okun (1981), a preocupação com a "justiça" (fairness) está no âmago da determinação de preços. Okun chamou a atenção para os fatores que elucidam por que os preços respondem mais a mudanças de custo do que as mudanças de demanda. O aspecto crucial seria "not rigid or sticky prices, but rather flexibility of prices in following costs even when demand is pulling in the opposite direction" (Okun, 1981, p. 169). Okun sugeriu que essa assimetria adviria, em boa medida, de "implicit contracts or conventions that introduce a concept of fairness in the relations between suppliers and customers whereby price increases based on cost increases are generally accepted as fair, but

5 A ideia da necessidade da estabilidade pode ser encontrada também em Hicks (1974, p. 78, p. 84).

6 Para essa ideia de "preço justo", ver também Hicks (1974, p. 79). 
many that might be based on demand increases are ruled out as unfair" (Okun, 1981, p. 170).

Essas características institucionais moldam um ambiente no qual as firmas são levadas a considerar que os consumidores têm uma percepção do que seria um "preço justo", e mantém tal percepção - pelo menos enquanto a firma em questão não "cobre a mais" ou não abuse do seu poder. Vendedores e consumidores, bem como trabalhadores e empregadores, tendem a embarcar em compromissos de longo prazo, com o objetivo de evitar ou minimizar os efeitos de novidades "perturbadoras" (embora essas sejam inevitáveis).

Em um mundo de incerteza fundamental, o caráter convencional dos preços, resultado de um processo interativo onde demandas conflitantes estão sempre em jogo, espelha a busca recorrente por estruturas estáveis que podem fornecer informações importantes e propiciar as decisões na vida econômica. ${ }^{7}$

\section{0 processo de formação de preços como convenção}

As explicações tradicionais na análise econômica, de teor neoclássico, garantem que os preços são determinados para se alcançar a maximização de lucros, através da igualdade entre custo marginal e receita marginal. Assim, os preços são "guiados pela demanda" e garantidores de um market-clearing.

Entretanto, o comportamento convencional no âmbito da precificação é, no mundo real, basicamente "guiado pelos custos". Afirmar que os preços resultam da igualação da demanda e da oferta via procedimentos de maximização do lucro é uma interpretação estreita da realidade. ${ }^{8}$ As ações das

7 A ideia de Hicks (1974) de preços fixos e flexíveis (fixprice-flexprice) é útil para explicar essa necessidade de regras estáveis na formação de preços, porém por um ângulo diferente. Por exemplo, em um sistema fixprice, os preços tendem a ser fixos ou estáveis, pelo menos no curto prazo, não só porque em um mundo onde as firmas normalmente operam abaixo de sua capacidade total os ajustes a variações da demanda são normalmente feitos em termos de quantidades, mas, também, porque as convenções fornecem alguma estabilidade e continuidade nas "regras do jogo". Nesse contexto, as convenções podem ser entendidas como uma propriedade social emergente, no sentindo dado por Lawson (2003, p.183), de um sistema econômico descentralizado, permeado pela incerteza.

8 Guardadas as devidas diferenças teóricas, Marx já havia notado a inadequação de se considerar a oferta e demanda enquanto determinantes dos preços, ao mesmo tempo que aponta para a relevância dos custos: "This clever man does not understand that in the case in question it is 
firmas não podem ser facilmente reduzidas a uma mera política de otimização, tendo em vista as inevitáveis considerações estratégicas presentes no processo decisório das mesmas..$^{9}$ Isto é, os preços são a resultante de uma série de fatores que influenciam a atividade econômica, de várias forças em ação. Os preços finais são a síntese de uma vasta gama de elementos que circunscrevem e capacitam o comportamento e o desempenho da firma.

Com efeito, uma abordagem institucionalista do processo de formação de preços deve contemplar, segundo Hodgson (1998, p. 170):

All aspects of the institutions that are closely bound up with the process of price formation are relevant. What are the costs and how are they evaluated? What routines govern the calculation of prices? What information is available and what is unknown? By what routines is information obtained and used? What routines are used to revise prices in line with the experience on the market? What is the strategy concerning competitive pricing? How does this relate to market structure?

Nesse sentido, é possível argumentar que a formação de preços passa pela consideração da influência de dois conjuntos de fatores. O primeiro é a estrutura na qual a firma está imersa. Essa estrutura coloca restrições ao comportamento da firma no que tange à formação de preços, como as formas de concorrência, a tecnologia requerida para produzir e investir, a ação dos sindicatos, as formas de regulação etc., mesmo considerando que a intensidade de cada uma dessas restrições possa mudar com o tempo. O segundo é o domínio típico da decisão da firma, no qual desempenham papel importante a experiência passada, a estrutura de custos e as estratégias de sobrevivência ou crescimento. A interação desses dois conjuntos de fatores condiciona o processo de formação de preços.

É importante enfatizar, ainda, a conhecida distinção entre setores em que os preços são principalmente determinados por um mark-up sobre os custos e aqueles em que são determinados pela oferta e demanda. Como ressaltou Joan Robinson (1977, p. 18-19), grande parte do setor agrícola e das indústrias extrativas são exemplos desses últimos, enquanto a indústria manufatureira, em geral, ilustra os primeiros.

precisely the change in cost of production, and also therefore in value, that has brought about the change in demand, i.e. in the relationship of demand and supply, and that this change in demand can induce a change in supply. This would however prove completely the opposite of what our theorist wants to prove, which is that the change in cost of production is in no way governed by the relationship of demand and supply, but on the contrary is what governs this relationship." (Marx, 1894, p. 293).

9 "[T]he goal of management is not to maximize profits but to survive and grow to the full extent permitted by external circumstances" (Arestis, 1992, p. 144). 
Nos mercados oligopolísticos, as firmas não são tomadoras de preço, mas, sim, formadoras de preço, pois elas têm poder para decidir seus preços. ${ }^{10}$ As firmas fixam os preços e ajustam a produção de acordo com oscilações na demanda. A oferta se ajusta à demanda através de mudanças no uso da capacidade. As decisões de preços das firmas são também influenciadas pelas decisões de preços de outras firmas que competem no mesmo mercado ou indústria, o que significa que um aspecto importante da realidade econômica é a intersubjetividade inerente à formação de preços. ${ }^{11}$

A operação sistemática com plena capacidade tende a aumentar os custos e, assim, os preços. O excesso de capacidade é uma característica típica da rotina da firma e os preços são governados por um mark-up sobre os custos. Os efeitos da demanda sobre os preços são percebidos ao nível da plena utilização da capacidade instalada, ou próxima a ela, mas não em condições normais. Essa abordagem da determinação de preços considera, portanto, a existência de capacidade ociosa e o emprego de recursos abaixo do pleno como a "norma", com o excesso de demanda exercendo influência sobre as decisões de preço somente em circunstâncias excepcionais.

Em vista disso, a mais típica convenção seguida por firmas é a de que os preços são guiados por custos ou formados em uma base cost-plus, a um nível padrão (convencional) de utilização da capacidade tendo em vista uma taxa de retorno desejada. Essa ideia inspira-se nos trabalhos de Hall e Hitch (1939), Kalecki (1971, cap. 5), Steindl (1952), Eichner (1973) e Sylos-Labini (1969), entre outros. ${ }^{12}$ Como afirmou Marc Lavoie (2014, p. 167):

The cause of this is that prices are not designed to be market-clearing prices; rather they are reproductive prices. The purpose of prices is to ensure that efficient or average firms generate enough profits through the cycle to finance or obtain finance for the required investments.

10 Vale observar, no entanto, que mesmo firmas pequenas podem não ser tomadoras de preço: "all firms, however small, are demand-constrained, ... none are price-takers in the sense embodied in the modern theory of perfect competition, (...) supply curves can be drawn for any firm, and ... the elasticity of demand a firm faces depends on its size and whether it acts alone or in concert with others in the industry. (...) [E]ven a perfectly certain small firm cannot sell an indefinitely large amount at the going price. This is the crucial issue, for compatibility with the Principle of Effective Demand depends on firms' demands being determined by aggregate demand" (Chick, 1992, p. 162, p. 149-150).

11 Para uma discussão mais aprofundada de abordagens teóricas que reconhecem a natureza intersubjetiva da realidade econômica, ver Fullbrook (2002).

12 Para abordagens mais recentes sobre formação de preços sob uma perspectiva heterodoxa, ver, por exemplo, Lee (1998), Downward (1999), Lavoie (2001), Shapiro; Sawyer (2003) e Lavoie (2014). 
Assim, os preços são definidos de acordo com mark-up, que é adicionado, basicamente, sobre os salários nominais e os preços das matérias-primas principais elementos dos custos variáveis. Por sua vez, o mark-up ajuda a compor uma espécie de "fundo" para as operações da firma. As necessidades financeiras das firmas e o poder de monopólio que elas podem exercer governam, portanto, o mark-up (Arestis, 1992, p. 139). O mark-up torna-se, assim, uma estratégica "variável de decisão":

The mark-up that connects the product price to the product costs is a decision variable (...) Changes in the price depend on their effects on the enterprise, and while the price can shift with the product's costs, it will do so if and only if the price change serves the ends of the enterprise. The mark-up price is firm determined rather than cost (or demand) determined, and it is the firm's determination of the price that relates it to the product's costs (Shapiro; Mott, 1995, p. 36).

A determinação da margem de lucro pelas firmas e, portanto, do próprio mark-up, depende, sobretudo, daquilo que os agentes consideram "razoável" (reasonable) (Robinson, 1947, p. 78).

$\mathrm{Na}$ presença de incerteza, as firmas definem seus preços com base em convenções que ajudam a simplificar algumas atividades práticas que, caso não houvesse as convenções, seriam altamente complexas. A abordagem da precificação com base no cost-plus é, então, a convenção que as firmas utilizam sem ter que se preocuparem com um grande número de decisões complicadas, como cálculos de receita marginal, custos marginais e adoção de procedimentos de otimização. Ao mesmo tempo, ainda que os agentes isoladamente estejam apenas lutando pela própria sobrevivência enquanto capitalistas ao se conformarem a esse procedimento, a formação de preços fundada nos custos garante que as atividades econômicas se reproduzam enquanto tais. Parafraseando Marx (1890, p. 166-167): eles não sabem, mas fazem.

Existem três versões de modelos de precificação com base no cost-plus: mark-up, custo total (custo normal) e "retorno-meta" (target-return). Mesmo que sejam diferentes nos detalhes, todos expressam, essencialmente, a mesma ideia: os preços mudam de acordo com mudanças nos custos, em particular os relativos aos salários nominais e às matérias-primas. ${ }^{13}$

Como regra, a "taxa desejada de retorno" (target rate of return) é uma "taxa de lucro convencional" e não se pode admitir sua estrita correspon-

13 Ver Lavoie (2014, cap. 3), Lee (1998) e Downward (1999) para tratamentos mais detalhados. 
dência com a taxa de lucro realizada, nem no curto nem no longo prazo. As firmas têm informação somente sobre as taxas de lucro passadas; isto é, elas não têm como saber como as taxas futuras serão. Elas contam com alguma medida convencional da taxa de lucro que se supõe irá cobrir parte dos custos associados à expansão da firma, tanto passados quanto futuros (Lavoie, 2014).

As decisões de preços envolvem expectativas que abrangem tanto o curto quanto o longo prazo. Assim, as convenções que as governam estão relacionadas, em um sentido especial, aos objetivos específicos das firmas. Por exemplo, o preço de um certo nível de produção (dado o estoque de capital) é a expressão de custos incorridos no período de produção. As pressões de demanda, exceto em circunstâncias excepcionais, desempenham papel secundário no curto prazo. No entanto, os preços não são definidos somente com o propósito de reproduzir as condições de produção, mas também com o objetivo de transformá-las através da criação de fundos para investir e expandir o estoque de capital da firma. Em outras palavras, o horizonte de tempo e as expectativas relevantes associadas com as diferentes decisões envolvem diferentes convenções.

Fatores de curto prazo estão relacionados a mudanças no nível de produção, no qual os custos normais podem mudar, mas a margem de lucro tende a permanecer constante. Nesse caso, a regra seguida é a da precificação com base no cost-plus.

Entretanto, as firmas operam com um horizonte de tempo que vai além do período de produção corrente. ${ }^{14}$ A formação de preços está, portanto, de alguma forma associada ao processo de acumulação. Nesse caso, no qual as decisões de investimento afetam as decisões de preço, as firmas seguem a regra de precificação com base no target-return: o propósito principal da precificação torna-se, então, a taxa de retorno sobre o capital empregado. Agora, não somente o custo normal, mas também a margem de lucro pode variar. Para um dado nível de custos unitários, quanto maior o nível de investimento, maior o nível de preços desejado pelas firmas.

A firma fixa seu preço na expectativa de que um certo montante de lucros será obtido no futuro. Expectativas de expansão e de sobrevivência no longo prazo estão sempre presentes. Assim, se o horizonte de tempo afetar os objetivos da firma, então o lucro corrente não é a única variável 14 "[T]he pricing decision can no longer be separated from investment planning as in the case of the conventional theory of the firm" (Arestis, 1992, pp. 144-145). 
que atrai sua atenção, mas também os lucros futuros. A firma observa com atenção os impactos de longo prazo de suas decisões correntes de preço. Como Shapiro e Mott (1995, p. 41) corretamente enfatizaram:

While the mark-up is decided in the short run, the firm that decides its level looks to the long run. The product pricing of the firm is forward looking and strategic, and because it is, the results of the pricing cannot be determined under the confines of the short run.

Outro aspecto institucional na formação de preços é o reconhecimento tácito de um sistema de liderança de preços: competidores num mercado específico seguem um líder, imitando sua política de precificação. A prática de seguir o líder espelha a propriedade importante de interdependência das ações que caracteriza a vida econômica e social, como mencionado anteriormente. $O$ preço definido por uma firma sofre a influência dos preços definidos por outras firmas. Além disso, não somente os competidores reais, mas também os competidores potenciais influenciam as decisões de preço: barreiras à entrada e preços de exclusão desempenham um papel importante na determinação de preços. Tais práticas são conhecidas por todos os que operam em um mercado específico e contribuem para evitar guerras de preços devastadoras. Essa característica intersubjetiva pode, em alguns casos, possibilitar conluios (implícitos ou explícitos). ${ }^{15}$

As firmas conhecem o caráter interativo da determinação de preços porque elas normalmente seguem a empresa líder. Esse comportamento torna-se o mais razoável nessas circunstâncias. Elas veem o líder como a referência para todas as firmas concorrentes. Em geral, a firma líder é aquela com a maior parcela de mercado e/ou custos de produção mais baixos. A política de seguir o líder é convencional, no sentido de que depende de um acordo geral implícito ou um entendimento compartilhado entre os participantes de um mercado que, de outro modo, poderia causar consequências piores para muitos, na forma de instabilidade indesejável e desnecessária (porém, é importante notar que a inovação no interior desse mesmo processo pode engendrar a ruptura dos procedimentos gerais predominantes que possibilitam a ação).

15 Não somente a prevenção à entrada de novas firmas pode afetar a determinação de preços, mas também outros fatores como, por exemplo, a intervenção governamental. Contudo, é importante enfatizar que há competição também em um âmbito não apenas restrito a decisão de preço: provisão de serviços especiais para os clientes, ênfase na qualidade do produto, pronta entrega, arranjos financeiros facilitadores do consumo etc. Atualmente, essas práticas parecem ter se tornado ainda mais importantes. 
O líder determina um preço que seja capaz de reproduzir as necessidades correntes de produção e/ou criar o financiamento necessário para dar suporte aos planos de investimentos desejados que atenderão os objetivos de crescimento da firma. Assim, uma parcela importante dos fundos para investimento é gerada internamente à firma, advinda dos lucros. Com certa estrutura de preços na indústria na qual a firma líder opera, as posições relativas são mantidas ou modificadas quando o líder altera os preços e os liderados o seguem.

Uma restrição adicional na definição do mark-up pode ocorrer se a imitação das ações do líder não for perfeita ou imediata. O líder não tem controle total das consequências de suas decisões (nem das decisões dos outros) e não pode antecipar perfeitamente as reações de seus competidores após qualquer mudança nos preços. Essa incerteza quanto a uma possível perda de vendas para outras firmas, mesmo que mediada pelo tamanho da parcela da produção e das vendas que o líder possui na indústria particular em que opera, está sempre presente. De fato, este é o caso mais realista, pois mesmo o líder não está totalmente protegido das pressões de concorrência, a despeito de sua posição estratégica em termos da definição das políticas de preço (e investimento) (Reynolds, 1989, p. 247-250).

\section{Instituições no mercado de trabalho}

No âmbito do mercado de trabalho, o aspecto mais relevante da determinação de salários é que as instituições são provavelmente mais importantes do que as condições de oferta e demanda. As decisões dos agentes nesse mercado são também influenciadas pelo costume, por normas associadas às remunerações e por crenças em relação à equidade no local de trabalho, nas firmas e na sociedade do modo geral. As "pressões normativas", isto é, "desires to enforce fair pay, (...) constrained by conventions" (Wood, 1978, p. 53), têm um papel crucial e tão importantes quanto as "pressões anômicas" (anomic pressures), isto é, aqueles fatores associados ao mercado e a forças conjunturais (excesso e escassez no mercado de trabalho). As pressões normativas dão um papel significativo aos mecanismos "extramercado", como a preocupação com a "justiça" das taxas de lucros observadas, a estrutura dos salários relativos, ou a ênfase nos níveis costumeiros de consumo possibilitados pelos níveis de renda habituais passados. A barganha 
salarial coletiva tende a ser a regra, e não a oferta e demanda de trabalho em nível individual. Como observou Townshend (1937, p. 165):

\begin{abstract}
everyone knows the enormous resistance to either rises or falls in money-wages - a resistance based surely on real conventions, firmly established both among employers and employed, and governing their offers, that rapid changes in money-wages are undesirable, and wide fluctuations from the conventional norm in some way "unjust" to one party or the other.
\end{abstract}

Em sua abordagem do mercado de trabalho enquanto uma "instituição social", Robert Solow enfatizou que as taxas de salários e os níveis de emprego não são exatamente como outros preços e quantidades, o que faz com que o mercado de trabalho possua algumas características distintivas: "it cannot be understood without taking account of the fact that participants, on both sides, have well-developed notions of what is fair and what is not" (Solow, 1990, p. 3).

A influência de fatores históricos, sociais e institucionais no mercado de trabalho foi reconhecida por vários autores. Por exemplo, Keynes fez alusão aos "social factors which influence the level of the money wage" (Keynes, 1937, p. 121). Hicks, por sua vez, reforçou a importância da justiça dos contratos salariais (Hicks, 1974, cap. III). O julgamento dos trabalhadores a respeito de "salários justos", de tratamento justo pelos empregadores, inclui não apenas uma comparação com os rendimentos de outros trabalhadores, mas também com sua própria experiência passada, bem como a avaliação do que seria um "lucro justo". O costume e a tradição estabelecem o que se espera de um sistema justo de salários. Taxas salariais "padrão" são reforçadas a cada rodada de negociações. Por exemplo, os salários podem até aumentar em setores que não estão se expandindo, nesse caso, não devido a escassezes, mas devido a uma percepção de "injustiça" (unfairness) (Hicks, 1974, p. 71). Tais percepções estão no cerne da resistência à queda de um poder de compra com o qual se está acostumado. Os elementos de interdependência são também fortes nessa interpretação do papel das instituições no mercado de trabalho.

Como mencionado anteriormente, Adrian Wood (1978, cap. 3) reconheceu que as "pressões normativas" podem influenciar os salários mais do que as "pressões anômicas". Na definição de remunerações e salários, a preocupação com as posições relativas e as comparações com um conjunto de trabalhadores e empregos que servem como referência estão sempre presentes. Os agentes buscam a preservação das posições relativas, passadas e presentes. Os conflitos acerca de "relatividades justas" sempre 
existirão. Os trabalhadores irão considerar o que é tido como um salário relativo justo ou uma parcela justa de lucros (Arestis, 1992, p. 153). Para Wood (1978, p. 22), portanto, a preocupação com um pagamento justo em termos relativos pode ser mais importante do que as demandas por remunerações justas em termos reais. Nesse contexto, o processo de estabelecimento do salário-mínimo como mecanismo institucional formal com o intuito de assegurar uma cesta de consumo básica para a classe trabalhadora é, aqui, emblemático. Historicamente, a definição do salário-mínimo e de outros mecanismos, formais e/ou informais, de garantia do básico socialmente aceito para a reprodução da classe trabalhadora foi fruto da luta política nas quais considerações sobre justiça e posições relativas no leque de rendimentos desempenharam relevante papel.

De modo similar, Okun (1981) chamou a atenção para os compromissos e arranjos de longo prazo entre a firma e seus empregados como uma característica típica dos acordos salariais. Há um "grau de rigidez" envolvido nas decisões de ofertar e aceitar empregos, não relacionado exclusivamente ao montante técnico do insumo trabalho no processo de produção, nem a barreiras legais e contratuais para contratação e demissão:

It is the initial establishment of a relationship between an employer and an employee that imposes a "set-up" cost, and that cost is generally shared by both employer and workers. As a result, the employer will have an investment in workers, and workers will have an investment in their firm (Okun, 1981, p. 75-76).

Em outras palavras, os salários são o resultado de um processo de barganha entre trabalhadores e empregadores, no qual uma série de fatores está presente. A definição de salários reflete a competição e a luta para manter ou melhorar as posições relativas. Desse modo, a determinação do salário nominal decorre de um conflito sobre as parcelas relativas da renda (Kalecki, 1971, cap. 14).

Os trabalhadores tentam definir seus salários com base em aspirações relativas a um determinado "salário-meta" que expresse tanto a preocupação com a distribuição funcional entre salários e lucros, como com uma distribuição intersalários. As negociações salariais concentram-se em três aspectos: a) a preservação do salário corrente; b) a obtenção de um "salário real-meta", e c) o restabelecimento de diferenciais de salário (cf. Arestis, 1992, p. 164-166).

Em primeiro lugar, as negociações de salário começam com os trabalhadores tentando manter o nível corrente de salário. Eles contrastam sua 
situação corrente com a passada e tentam obstruir qualquer piora no poder de compra com o qual estão acostumados. Se necessário, uma revisão do poder de compra pode ser demandada. Ocasionalmente, a deterioração do salário real devido à inflação passada será levada em consideração na rodada subsequente de negociações.

Em segundo lugar, diferenças percebidas entre o salário corrente e o "salário-meta" aspirado levarão a demandas por compensações. A percepção de que a diferença entre o salário corrente e a meta aspirada é muito alta levará a pressões muito fortes para diminuir ou eliminar esse hiato. Consequentemente, o grau de militância pode aumentar.

Em terceiro lugar, os trabalhadores levam em conta sua posição na estrutura relativa de salários (como Keynes já havia enfatizado). Quedas de salário encontram oposição porque isso levaria a uma redução dos salários relativos. Compromissos com relatividades salariais restringem a queda das taxas de salário, mesmo num contexto de alto desemprego. A racionalidade aí subjacente é que os trabalhadores de um setor não aceitam passivamente aumentos de salário de outros trabalhadores. Caso isso aconteça, eles tentarão aumentar seus próprios salários.

Por analogia ao caso dos preços no mercado de bens, é possível afirmar que há liderança e imitação também no mercado de trabalho. Tendo em vista a busca por "relatividades justas", os melhores acordos salariais irão se tornar a referência que as outras negociações futuras irão considerar. Nesse caso, o "líder" define um padrão que os "imitadores" tentarão atingir (Lavoie, 2014, p. 548).

Os salários nominais são, em grande medida, um elemento "exógeno" na determinação de preços. Seus determinantes principais devem ser buscados nas circunstâncias históricas, políticas e sociais, as quais não podem ser completamente teorizadas por meio, exclusivamente, da análise econômica se o objetivo for o de fornecer uma interpretação mais abrangente dos eventos em questão (Lavoie, 2014, cap. 3).

\section{0 processo inflacionário}

A esta altura, é possível esboçar alguns elementos para uma discussão do fenômeno da inflação com ênfase no papel das instituições. Na perspectiva heterodoxa, a inflação é, normalmente, um evento decorrente de custos, e 
não impulsionado exclusivamente pela demanda. Se os preços são definidos em um nível "micro", a inflação é determinada em um nível "macro". Mas o processo inflacionário é também influenciado por convenções, normas, regras, hábitos etc., que atuam nos vários mercados. A inflação é um fenômeno ligado aos custos das firmas e a um conflito sobre os rendimentos (salários, lucros etc.) gerados nos processos capitalistas de produção.

$\mathrm{Na}$ raiz do processo inflacionário, excetuando os contextos de excesso "anormal" de demanda ou os choques imprevistos sobre a estrutura de custo da firma (como desvalorização cambial súbita, mudanças bruscas nas taxas de juros ou nos impostos, quebras de safra etc.), devem-se contemplar também os impactos desestabilizadores decorrentes da ruptura de instituições (práticas) bem-estabelecidas nos mercados de trabalho, financeiros e/ou bens, como, por exemplo, a ausência, em um setor específico da economia, de um acordo entre empregadores e trabalhadores sobre o que seria um salário justo ou uma taxa de lucro justa. Se esse setor possui um peso importante, esse conflito pode irradiar-se para o restante das negociações salariais e gerar um impasse de grandes proporções.

Eventos inesperados ou certas inovações, possibilitadas pelas próprias instituições, podem também abalar as estruturas institucionais existentes e comprometer a "normalidade" e estabilidade do estado corrente de coisas. Assim, esses eventos podem ser fortes o suficiente para induzir uma revisão parcial ou total do conjunto de convenções de forma a reaver uma nova perspectiva de preços estáveis.

A inflação pode ser vista como o resultado agregado de vários fatores (cambiantes) que afetam os custos das firmas, a lucratividade e as condições de demanda efetiva. Uma explicação mais abrangente dos determinantes da inflação deve, portanto, contemplar os seguintes fatores:

a) Os objetivos das firmas no que diz respeito aos seus planos de expansão, que podem causar alterações da taxa de lucro desejada e no mark-up;

b) Mudanças na taxa de salários nominais;

c) Deslocamentos relevantes da produtividade do trabalho;

d) Ocorrência periódica de choques (em decorrência de mudanças inesperadas, por exemplo, na tributação, nas taxas de juros, nos preços de insumos estratégicos etc.);

e) Variações do nível de utilização da capacidade em resposta a mudanças na demanda efetiva;

f) Mudanças nos custos expressas por alterações nos preços das com- 
modities, através do efeito combinado do nível de atividade mundial e da taxa de câmbio;

g) A formação das taxas de câmbio em decorrência do comportamento dos fluxos de capital e da condução da política econômica;

h) Fratura e colapso do conjunto de instituições (práticas sociais) familiares predominantes nos vários mercados (como, por exemplo, as preocupações com as "relatividades justas", que afetam a barganha salarial e a estrutura global de salários, bem como as percepções sobre "taxas de lucro justas").

Em suma, a demanda é apenas um fator em um conjunto mais complexo de elementos que concorrem, simultaneamente, em diferentes velocidades, formas e intensidades, para determinar a taxa de inflação de um país em um dado contexto histórico.

\section{Regimes de inflação e instituições}

Com base na discussão anterior, é possível ainda discutir como diferentes instituições operam sob regimes distintos de inflação. Uma taxonomia familiar para analisar experiências de inflação classifica o fenômeno inflacionário em termos de: a) inflação baixa (ou moderada), b) inflação alta (inercial ou crônica) e c) hiperinflação. Em vez de discutir essas experiências em termos de uma taxa de inflação mensal mensurável, parece mais adequado analisá-las em termos das instituições (práticas sociais) familiares às quais os agentes recorrem em cada situação específica. Não há uma preocupação aqui com o limite quantitativo, bem definido e preciso, a partir do qual se pode afirmar com segurança que houve uma "mudança de regime", mas, sim, com os comportamentos peculiares associados a cada episódio inflacionário.

Em economias com inflação baixa, as mudanças de preço são governadas basicamente por mudanças nos custos e no mark-up, com as condições de demanda exercendo um papel secundário. As mudanças de preço em um setor não se proliferam completamente sobre o restante da economia. Os aumentos de preços em determinados setores da economia são absorvidos sem que se observem impactos de longo alcance na economia como um todo. A inflação passada não é completamente reproduzida no presente. A transmissão dos resultados passados para o presente não é per- 
feita. Mesmo que alguns agentes ou firmas deparem-se com uma inflação localizada mais alta do que a taxa de inflação da economia como um todo, o comportamento típico consiste em agir como se esses aumentos não fossem permanentes. As expectativas de estabilidade são, portanto, mais arraigadas e duradouras. Assim, grandes choques localizados podem ter um efeito geral comparativamente pequeno.

Em economias sob inflação crônica ou alta, por outro lado, o passado tem uma influência quase que de um para um sobre o presente. Mecanismos de propagação entram em operação via indexação (formal e informal) de contratos. A inflação do último período torna-se uma predição bastante razoável da inflação corrente e futura. O objetivo da indexação de contratos por meio de reajustamentos frequentes dos rendimentos é reaver os ganhos reais habituais no começo de cada período de indexação. A inflação passada constitui um "piso" para a inflação subsequente, engendrando um padrão inercial. Seguir a trajetória da inflação passada torna-se, então, a principal convenção a governar a formação de preços. Choques de preços localizados podem ter um efeito proporcionalmente grande na taxa de inflação.

Em episódios de hiperinflação, a influência peculiar da inflação passada na determinação das taxas de inflação correntes e futuras, típica de regimes de inflação alta, é abolida. A convenção agora é a de que o futuro será muito "pior" do que o presente. As mudanças de preço, hoje, são mais altas do que as passadas, e os agentes acreditam (e sabem!) que as taxas futuras serão mais altas do que as presentes. Sob tais circunstâncias, o comportamento razoável (convencional e defensivo) tem como base a expectativa de que as taxas de inflação crescerão ao longo do tempo. Consolida-se a crença da aceleração inflacionária (talvez explosiva). A inflação passada define um piso para a trajetória futura da inflação, que sempre se move para cima. As expectativas são altamente elásticas e a instabilidade (quase absoluta) vigora. Assim, pequenos choques podem ter impactos fortes e generalizados.

Em uma hiperinflação, a moeda doméstica tende a perder sua função de reserva de valor, e é gradualmente substituída por uma divisa estrangeira ou por outro substituto que seja confiável. Instala-se o fenômeno da "fuga da moeda". Os contratos celebrados entre os agentes tendem a ser encurtados. Uma maior incerteza e a percepção de imprevisibilidade radical dos acontecimentos levam a uma diminuição dos horizontes temporais nos 
processos decisórios. As decisões de investimento, por razões óbvias, são as mais afetadas. ${ }^{16}$

Em resumo, dependendo do tipo de inflação examinado, verificam-se tipos distintos de instituições que governam os comportamentos dos agentes. Mas, é necessário frisar, existem práticas típicas que estão presentes em qualquer tipo de inflação (seguir a abordagem cost-plus e/ou avaliar a justiça da situação corrente). O ponto importante a ser considerado é que backgrounds históricos distintos podem engendrar padrões de pensamento ou comportamento socialmente compartilhados condicionados por esses contextos históricos. Consequentemente, instituições fortemente relacionadas a um contexto histórico específico podem se tornar mais evidentes e se sobreporem às instituições que se mostram mais duradouras, sem nunca eliminar, porém, a operação destas últimas. Por exemplo, demandas por indexação informal, em regimes de inflação crônica, explicitam uma dimensão particular do processo de formação de preços em uma economia capitalista, com base no mark-up e nos custos de produção, mas que não se manifestam em contextos históricos distintos (tais como sob inflação baixa). Em outras palavras, a questão é elucidar como, sujeitas as restrições contextuais, as instituições são ativadas, reproduzidas e transformadas.

\section{Observações finais}

Este artigo teve como objetivo discutir a operação das instituições na determinação de preços. Convenções, regras, rotinas etc. são procedimentos que possibilitam a gestão dos negócios e a definição dos preços. Em condições de incerteza, elas sustentam certas operações que, em sua ausência, seriam provavelmente inviáveis de um ponto de vista prático. Portanto, elas ajudam a promover a coordenação das ações.

Uma instituição-chave é a convenção da precificação com base no costplus. Preços do tipo cost-plus não são entendidos aqui como preços do equilíbrio de mercado, influenciados exclusivamente por variações de curto prazo na demanda. A presente abordagem também não os entende como meros "alocadores de recursos", ou índices de escassez temporária, mas, ver, por exemplo, Arida (1986), Bresser-Pereira e Nakano (1986), Lopes (1986), Kandir (1989) e Carvalho (1991). 
sim, como "preços administrados" (à la Gardiner Means). Eles são definidos de forma a cobrir os custos de produção e para financiar os planos de expansão da firma. Nesse sentido, os preços são tanto "reprodutivos" como "transformadores", pois devem permitir que as operações das firmas ocorram não somente hoje, mas também amanhã (idealmente em condições mais vantajosas).

Se os preços são "mecanismos de reprodução", que permitem as firmas realizarem continuamente suas atividades básicas, eles também podem ser mecanismos de transformação. Inovações bem-sucedidas têm o poder de romper convenções preestabelecidas, regras e rotinas familiares aos agentes, bem como moldá-las e criar novas. Não raro, a mudança estrutural engendrada pela atividade da inovação pode forçar mudanças significativas de preços, redefinindo convenções. No longo prazo, preços mais baixos e novos arranjos institucionais são resultado de inovações bem-sucedidas induzidas pela luta competitiva ativa, viabilizada pelo ambiente institucional no qual se encontram e que acaba por remodelar esse mesmo ambiente.

Nesse sentido, os preços são, paradoxalmente, tanto estabilizadores quando "desequilibradores". Os preços expandem mercados, concentram indústrias, desenvolvem novas indústrias e financiam o investimento. A mudança estrutural é intrínseca (está sempre latente) à formação de preços. É a possibilidade mesma de transformação das estruturas que acompanha esse tipo de precificação que a faz tão importante (Shapiro; Mott, 1995, p. 45).

A rationale para a definição da maioria dos preços e salários não é a necessidade de "ajustar os mercados" (market clearing) no curto prazo, mas, sim, aspectos ligados a compromissos de prazo mais longo (como as relações fornecedor-consumidor e empregador-trabalhador), as preocupações com a justiça das posições relativas e a necessidade de financiar os planos de expansão da firma. Em grande medida, tais fatores como que "isolam" salários e preços dos efeitos de mudanças na demanda, e todos eles contribuem para ajustamentos em termos de quantidades no que diz respeito a produção e emprego.

Em resumo, este artigo buscou realçar alguns aspectos que são normalmente ignorados nas interpretações tradicionais da formação de preços. Os seguintes elementos foram enfatizados:

a) A precificação é um fenômeno condicionado por interações complexas entre os agentes (intersubjetividade), pois há liderança de preço e 
imitação, além da sempre presente preocupação com as "relatividades justas";

b) Os preços não são o resultado da ação de "forças determinísticas", muito menos a solução de equilíbrio de um problema de coordenação;

c) Pode muito bem ocorrer situações em que não exista conhecimento suficiente para informar quais são os preços "certos" (um estado em que a incerteza genuína prevalece). Em decorrência, as firmas recorrem ao "modo costumeiro de fazer as coisas", isto é, ao conhecimento tácito incorporado nos vários tipos de instituição;

d) Os preços correntes são uma referência básica para a tomada de decisão, mas podem se tornar "pontos de partida" quando a atividade da inovação for bem-sucedida;

e) Há relativa estabilidade, mas há também um certo elemento de precariedade na definição de preços, pois choques imprevisíveis podem ocorrer, e as forças da concorrência estão sempre ativas;

f) Mudanças nos preços não associadas à demanda podem decorrer de comportamentos não convencionais, desafiadores das regras e das rotinas bem-estabelecidas, que têm como objetivo gerar inovações bem-sucedidas e capturar lucros "anormais" no maior período de tempo possível.

\section{Referências}

ARESTIS, P. The Post-Keynesian Approach to Economics. Aldershot: Edward Elgar, 1992.

ARIDA, P. (Org.). Inflação zero. Rio de Janeiro: Paz e Terra, 1986.

BECKERT, J. Where do Prices Come From? Sociological Approaches to Price Formation. Socio-Economic Review, v. 9, n. 4, p. 757-786, 2011.

BACKHOUSE, R. The Penguin History of Economics. London: Penguin, 2002.

BRESSER-PEREIRA, L. C.; NAKANO, Y. Inflação e recessão. São Paulo: Brasiliense, 1986.

CARVALHO, F. A Post Keynesian Approach to Inflation, High Inflation and Hyperinflation. In: DAVIDSON, P.; KREGEL, J. (Ed.). Economic Problems of the 1990s. Aldershot: Edward Elgar, 1991.

CHICK, V. The Small Firm Under Uncertainty: A Puzzle of the General Theory. In: GERRARD, B.; HILLARD, J. (Ed.). The Philosophy and Economics of J. M. Keynes. Aldershot: Edward Elgar, 1992.

DEQUECH, D. Institutions, Social Norms, and Decision-Theoretic Norms. Journal of Economic Behavior \& Organization, v. 72, n. 1, p. 70-78, 2009. 
DOWNWARD, P. Pricing Theory in Post Keynesian Economics: A Realist Approach. Cheltenham: Edward Elgar, 1999.

EICHNER, A. S. A Theory of the Determination of the Mark-up Under Oligopoly. The Economic Journal, v. 83, n. 332, p. 1184-1200 1973.

FULLBROOK, E. (Ed.). Intersubjectivity in Economics - Agents and Structures. London: Routledge, 2002.

HALL, R. L.; HITCH, C. J. Price Theory and Business Behaviour. Oxford Economic Papers, n. 2, p. 12-45, 1939.

HARROD, R. Economic Essays. London: Macmillan, 1952.

HICKS, J. The Crisis in Keynesian Economics. Oxford: Blackwell, 1974.

HODGSON, G. M. The Approach of Institutional Economics. Journal of Economic Literature, v. 36, n. 1, p. 166-192, 1998.

HODGSON, G. M. What Are Institutions? Journal of Economic Issues, v. 40, n. 1, p. 1-25, 2006.

HODGSON, G. M. Conceptualizing Capitalism: Institutions, Evolution, Future. Chicago: University of Chicago Press, 2015.

KALECKI, M. Selected Essays on the Dynamics of the Capitalist Economy, 1933-1970. Cambridge: Cambridge University Press, 1971.

KANDIR, A. A dinâmica da inflação. São Paulo: Nobel, 1989.

KEYNES, J. M. The General Theory of Employment. The Quarterly Journal of Economics, v. 51, n. 2, p. 209-223, 1937. In: KEYNES, J. M. The Collected Writings of John Maynard Keynes, v. XIV. London: Macmillan, 1973.

LAVOIE, M. Pricing. In: HOLT, R.; PRESSMAN S. (Ed.). A New Guide to Post Keynesian Economics. London: Routledge, 2001.

LAVOIE, M. Post-Keynesian Economics: New Foundations. Cheltenham: Edward Elgar, 2014.

LAWSON, T. Economics and Reality. London: Routledge, 1997.

LAWSON, T. Institutionalism: On the Need to Firm up Notions of Social Structure and the Human Subject. Journal of Economic Issues, v. 37, n. 1, p. 175-207, 2003.

LEE, F. Post Keynesian Price Theory. Cambridge: Cambridge University Press, 1998.

LITTLEBOY, B. On Interpreting Keynes. London: Routledge, 1990.

LOPES, F. O choque heterodoxo. Rio de Janeiro: Campus, 1986.

MARX, K. Capital, v. 1. London: Penguin, 1992 [1890].

MARX, K. Capital, v. 3. London: Penguin, 1993 [1894].

MONSALVE, F. Scholastic Just Price Versus Current Market Price: Is It Merely a Matter of Labelling? The European Journal of the History of Economic Thought, v. 21, n. 1, p. 4-20, 2014.

NEALE, W. Institutions. In: HODGSON, G.; SAMUELS, W.; TOOL, M. (Ed.). The Elgar Companion to Institutional and Evolutionary Economics, v. A-K. Aldershot: Edward Elgar, 1994.

OKUN, A. Prices and Quantities. Oxford: Basil Blackwell, 1981.

REYNOLDS, P. Kaleckian and Post-Keynesian Theories of Pricing: Some Extensions and Implications. In: ARESTIS, P.; KITROMILIDES, Y. (Ed.). Theory and Policy in Political Economy: 
Essays in Pricing, Distribution and Growth. Aldershot: Edward Elgar, 1989.

ROBINSON, J. An Essay on Marxian Economics. London: Macmillan, 1947.

ROBINSON, J. What Are the Questions? Journal of Economic Literature, v. 15, n. 4, p. 1318-1339, 1977. In: ROBINSON, J. Further Contributions to Modern Economics. Oxford: Basil Blackwell, 1980.

RUTHERFORD, M. Institutions in Economics: The Old and the New Institutionalism. Cambridge: Cambridge University Press, 1996.

SHACKLE, G. L. S. Epistemics and Economics. Cambridge: Cambridge University Press, 1972.

SHAPIRO, N.; MOTT, T. Firm-Determined Prices: The Post-Keynesian Conception. In: WELLS, P. (Ed.). Post-Keynesian Economic Theory. Dordrecht, Kluwer, 1995.

SHAPIRO, N.; SAWYER, M. Post Keynesian Price Theory. Journal of Post Keynesian Economics, v. 25, n. 3, p. 355-365, 2003.

SOLOW, R. The Labour Market as a Social Institution. Oxford: Basil Blackwell, 1990.

STEUART, J. Inquiry into the Principles of Political Economy, v. 1. London: A. Millar and T. Cadell, 1767.

STEINDL, J. Maturity and Stagnation in American Capitalism. New York: Monthly Review Press, 1976 [1952].

SYLOS-LABINI, P. Oligopoly and Technical Progress. Harvard: Harvard University Press, 1969.

TOWNSHEND, H. Liquidity-Premium and the Theory of Value. The Economic Journal, v. 47, n. 185, p. 157-169, 1937.

WOOD, A. A Theory of Pay. Cambridge: Cambridge University Press, 1978.

VELTHUIS, O. Talking Prices: Symbolic Meanings of Prices on the Market for Contemporary Art. Princeton: Princeton University Press, 2013.

\section{Sobre os autores}

Rogerio P. de Andrade-roger.andrade@uol.com.br Instituto de Economia, Universidade Estadual de Campinas, Campinas, São Paulo, Brasil. ORCID: https://orcid.org/0000-0002-9132-5307.

AlexWilhans Antonio Palludeto - alexwap@unicamp.br

Instituto de Economia, Universidade Estadual de Campinas, Campinas, São Paulo, Brasil. ORCID: https://orcid.org/0000-0002-1528-7548.

Os autores agradecem os comentários e sugestões de dois pareceristas anônimos.

\section{Sobre $o$ artigo}

Recebido em 12 de novembro de 2015. Aprovado em 16 de novembro de 2017. 